\title{
Selective Peripheral Dopamine-1 Receptor Stimulation with Fenoldopam in Human Essential Hypertension
}

\author{
Robert M. Carey, Robert M. Stote, Jeffrey W. Dubb, \\ Lloyd H. Townsend, C. Edward Rose, Jr., \\ and Donald L. Kaiser \\ Division of Endocrinology and Metabolism, Department of \\ Internal Medicine, University of Virginia Medical Center, \\ Charlottesville, Virginia 22908; Department of Medicine, \\ Presbyterian-University of Pennsylvania Medical Center and \\ Smith, Kline and French Laboratories, Philadelphia, \\ Pennsylvania 19104.
}

bstract. SKF 82526-J, or fenoldopam, a benzazepine derivative, is a selective dopamine-1 (DA1) agonist devoid of activity at dopamine-2, alpha- or beta-adrenergic receptors. We studied SKF 82526-J in 10 patients with essential hypertension and five normal control subjects on constant 150 -meq sodium, $60 \mathrm{meq}$ potassium intake. In the hypertensive patients, during a 6-d placebo period supine blood pressure and heart rate were stable at $156 \pm 6 / 105 \pm 4 \mathrm{mmHg}$ and $76 \pm 5$ beats/ min, respectively. In response to a single oral dose of $100 \mathrm{mg}$ of SKF 82526-J, supine blood pressure decreased to a nadir of $141 \pm 5 / 89 \pm 8 \mathrm{mmHg}(P<0.0001)$ at 90 min and remained decreased at $145 \pm 6 / 99 \pm 3 \mathrm{mmHg}(P$ $<0.0001)$ at $4 \mathrm{~h}$. Heart rate increased to $91 \pm 5$ beats/ min $(P<0.002)$, but returned to control levels $(82 \pm 5$ beats/min) at $4 \mathrm{~h}$. Renal blood flow increased from $371 \pm 57$ to a peak of $659 \pm 104 \mathrm{ml} / \mathrm{min}$ and renal vascular resistance fell from $34 \pm 5$ to $19 \pm 2$ dyn sec $\mathrm{cm}^{-5} \times 10^{3}$ $(P<0.01)$. Urine volume, sodium and fractional sodium excretion, and plasma renin activity were increased as a result of SKF 82526-J administration. During the ensuing 3 wk of SKF 82526-J, blood pressure remained decreased and returned to control levels after placebo administration. In contrast, in normal subjects SKF 82526-J administration was associated with a small transient reduction in diastolic pressure only.

Data from this work were presented in part at the Annual Meeting of the American Society for Clinical Investigation, May 1983, Washington DC.

Received for publication 4 June 1984.

J. Clin. Invest.

(c) The American Society for Clinical Investigation, Inc. $0021-9738 / 84 / 12 / 2198 / 10 \quad \$ 1.00$

Volume 74, December 1984, 2198-2207
These results suggest that reduced dopaminergic activity expressed at the peripheral DA-1 receptor may contribute to the pathophysiology and/or maintenance of increased blood pressure in essential hypertension. In addition, the results suggest that peripheral DA-1 receptor stimulation with SKF 82526-J may be efficacious in the treatment of human essential hypertension.

\section{Introduction}

In essential hypertension, the kidney has been considered a primary locus for the initiation and possibly maintenance of the hypertensive process $(1,2)$. Arterial blood pressure may be increased by resetting of pressure natriuresis. A higher renal perfusion pressure is thus required to excrete a sodium load, possibly due to afferent glomerular arteriolar constriction (2, 3). Conversely, the kidney also is affected by hypertensive vascular disease and renal blood flow may be diminished as a result of systemic arteriolar constriction (4-7). In support of these concepts, most studies to date have documented increased vascular tone in the renal vascular bed of patients with essential hypertension (8). Furthermore, the increased renal vascular resistance is reversible, as demonstrated by responsiveness to acetylcholine or dopamine, in most patients with essential hypertension (9).

Recently, several benzazepine derivatives have been found to be either full or partial agonists at dopamine receptors in the central nervous system and in peripheral tissues (10-14). One such benzazepine derivative is 6-chloro-7,8-dihydroxy-1(4'-hydroxyphenyl)-2,3,4,5-tetrahydro-(1H)-3-benzazepine, or SKF 82526 (10). Fig. 1 depicts the chemical structure of SKF 82526 as compared with that of dopamine.

The methane sulfonate derivative of SKF 82526 (SKF 82526-J or fenoldopam) is a potent dopamine agonist in the central nervous system and the renal vasculature (11-16). SKF 82526-J stimulates dopamine-sensitive adenylate cyclase in the rat caudate nucleus, an effect blocked by the dopamine antag- 
<smiles>NCCc1ccc(O)c(O)c1</smiles><smiles>Oc1ccc(C2CNCCc3c2cc(O)c(O)c3Cl)cc1</smiles>

Dopamine

(6-Chloro-7.8-dihydroxy-1-(4-hydroxyphenyl)2.3.4.5-tetrahydro-1H-3-benzazepine)

Figure 1. Chemical structure of dopamine and SKF 82526.

onists haloperidol, chlorpromazine, and bulbocapnine (13). SKF 82526-J has $\sim 3.5$-fold the potency of dopamine in renal vasodilation in the dog, an effect also blocked by the dopamine antagonists, bulbocapnine and metoclopramide (13-16). The compound is devoid of alpha- or beta-adrenergic receptor stimulating activity, is well absorbed orally, and does not cross the blood-brain barrier (13-16). SKF 82526-J does not inhibit nerve-evoked norepinephrine release $(13,14)$. Therefore, this compound is a potent, specific dopamine-1 (DA-1) ${ }^{1}$ agonist (10-16).

In normal man, SKF 82526-J increases renal blood flow (RBF) and sodium excretion (17). Since in essential hypertension renal vascular resistance is increased and may contribute to the pathogenesis of elevated blood pressure, we studied the effects of SKF 82526-J on blood pressure and renal function in essential hypertension.

\section{Methods}

Study design. The protocols were approved by the Human Experimentation Committee and written informed consent was obtained from all patients and normal subjects.

Hypertensive patients. 10 patients, 29-63 yr, with mild to moderately severe essential hypertension (supine diastolic blood pressure 95-120 $\mathrm{mmHg}$ ) were studied at the Clinical Research Center. Remediable causes of hypertension were excluded by normal renal arteriograms and other laboratory tests, including serum creatinine, electrolytes, and urinary vanillylmandelic acid excretion. All antihypertensive medications were discontinued at least $3 \mathrm{wk}$ before patients were admitted to the study. The days of the study were numbered consecutively beginning the day after admission, which was study day 1 . On the day of admission (study day 0 ), the patients were begun on placebo ( 1 capsule four times a day), which was continued through study day 6 in single blind fashion. On the morning of study day 1 , the patients were placed

1. Abbreviations used in this paper: DA-1 and DA-2, dopamine-1 and -2 , respectively; D5W, $5 \%$ dextrose solution; GFR, glomerular filtration rate; MAP, mean arterial pressure; $\mathrm{PAH}$, paraaminohippurate; RBF, renal blood flow; RPF, renal plasma flow.

on an isocaloric constant diet containing $150 \mathrm{meq}$ sodium and $60 \mathrm{meq}$ potassium per $24 \mathrm{~h}$ for the remainder of the inpatient part of the study. During the $14 \mathrm{~d}$ of inpatient study, consecutive 24-h urine samples were collected and analyzed for sodium, potassium, and creatinine; daily blood samples were obtained for serum sodium, potassium, chloride, bicarbonate, blood urea nitrogen, and creatinine; and daily weights were recorded. Blood pressure and heart rate were measured immediately before and $1 \mathrm{~h}$ after each oral dose of placebo or SKF 82526-J with a mercury sphygmomanometer by a technician who had no knowledge of the study protocol. Blood pressures were measured at 1-min intervals three times after the patients assumed the supine position for $10 \mathrm{~min}$, and again after upright posture for $2 \mathrm{~min}$.

No food was given after midnight before study day 7 , when the subjects assumed the supine position until completion of the study. At 6:00 a.m. on study day 7, a heparin lock for obtaining blood samples was placed in the left antecubital vein and an intravenous infusion of $5 \%$ dextrose solution (D5W) at $1 \mathrm{ml} / \mathrm{min}$ was begun in the right antecubital vein. At 6:30 a.m., an oral water load (tap water $20 \mathrm{ml} /$ $\mathrm{kg}$ ) was ingested and urine samples were collected at 30-min intervals for the remainder of the study. After each urine collection, a volume of water equal to the volume of urine passed during the previous 30 min period was ingested. At 8:30 a.m., a priming dose of sterile inulin (American Hospital Supply Corp., McGraw Park, IL) $(50 \mathrm{mg} / \mathrm{kg})$ and paraaminohippurate (PAH) (Merck and Co., West Point, PA) $(8 \mathrm{mg} /$ $\mathrm{kg}$ ) in D5W was administered intravenously and followed by a continuous sustaining infusion of inulin and PAH in D5W (calculated on the basis of predicted glomerular filtration rate [GFR] and renal plasma flow [RPF]) at $1 \mathrm{ml} / \mathrm{min}$ throughout the study. After the urine flow rate had stabilized for at least four consecutive 30 -min periods, control measurements were obtained during two consecutive $30-\mathrm{min}$ urine collection periods. Blood samples were obtained at the midpoint (10:30 and 11:00 a.m.) of each period for measurement of plasma renin activity, cortisol and aldosterone concentrations, and serum sodium, potassium, and prolactin concentrations. Immediately after the blood sampling at 11:00 a.m., a dose of SKF 82526-J $100 \mathrm{mg}$ was administered orally and urine was collected at 30 -min intervals for the ensuing $4 \mathrm{~h}$ (eight collection periods). Blood samples for plasma inulin, $\mathrm{PAH}$, osmolality, cortisol and aldosterone concentrations and renin activity and serum sodium, potassium, creatinine, and prolactin concentrations were obtained at the midpoint of each collection period for $4 \mathrm{~h}$ after SKF 82526-J administration. Blood pressure was monitored at 5-min intervals from 10:00 a.m. to 3:00 p.m. with an Arteriosonde automatic ultrasonic blood pressure recorder (Hoffman-LaRoche, Inc., Nutley, NJ). Heart rate was monitored by electrocardiograph lead II strip at 30 -min intervals over the same time period.

Beginning on study day 8 , SKF 82526-J $100 \mathrm{mg}$ four times a day was administered and continued through study day 14 . After midnight before study day 15 , no food was given and the patients were supine until 8 a.m. on study day 15 , when blood samples for plasma renin activity, cortisol, and aldosterone concentrations and serum electrolytes, creatinine, and prolactin concentrations were obtained from a heparin lock placed $2 \mathrm{~h}$ earlier. After completion of the blood and urine samples at $8 \mathrm{a} . \mathrm{m}$. On study day 15 , the patients were discharged from the Clinical Research Center for another 4 wk of outpatient study.

The patients then were followed in the outpatient section of the Clinical Research Center at weekly intervals. During the first 2 outpatient wk, the patients received SKF 82526-J $100 \mathrm{mg}$ four times a day orally; during the second $2 \mathrm{wk}$, placebo four times a day was substituted. Blood pressure and heart rate were recorded after $10 \mathrm{~min}$ supine three times and after 2 min standing three times. Blood samples 
for electrolyte and hormonal determinations were obtained at weekly intervals.

Normal subjects. Five normal white male subjects, 23-30 yr, with normal arterial blood pressure and no history of renal disease were also studied. Before study, the subjects were placed on a diet containing $150 \mathrm{meq}$ of sodium and $60 \mathrm{meq}$ of potassium per $\mathrm{d}$ for $5 \mathrm{~d}$. Electrolyte balance was verified by 24-h urine samples for sodium, potassium, and creatinine obtained on the two days prior to study and also on study day 1. No food was given after midnight before study day 1 . At 7:45 a.m. on study day 1 , the subjects were admitted to the Clinical Research Center. At 8:00 a.m., blood pressure and heart rate were measured at 1-min intervals three times with the subjects in the supine position for $10 \mathrm{~min}$ and again three times after upright posture for 2 $\mathrm{min}$. This procedure was repeated at 30-min intervals. At 10:00 a.m., $2 \mathrm{~h}$ after initiation of hemodynamic monitoring, SKF 82526-J $100 \mathrm{mg}$ or placebo was administered orally. Blood pressure and heart rate monitoring were continued at 30-min intervals for $3 \mathrm{~h}$ (until 1:00 p.m.), then hourly until 4:00 p.m., when a second dose of SKF 82526$\mathrm{J} 100 \mathrm{mg}$ or placebo was administered orally. Blood pressure and heart rate then were monitored at 30-min intervals for $1 \mathrm{~h}$, then hourly for $1 \mathrm{~h}$, then twice hourly until 10:00 p.m., when a third dose of SKF 82526-J or placebo was given. Blood pressure and heart rate again were measured at 12:00 midnight, after which time the subjects remained supine until completion of the protocol at 8:00 a.m. on study day 2. A fourth dose of SKF 82526-J was given at 4:00 a.m. on study day 2 .

After an interval of 2-4 wk on ad lib. diet, the same subjects were studied in an identical manner except that the alternative agent (SKF 82526-J or placebo) was administered. SKF 82526-J was provided by Smith, Kline and French Laboratories, Philadelphia, PA.

Analytical methods. All blood samples were collected in tubes on ice and centrifuged immediately, and the plasma was separated and frozen until time for assay. Samples for plasma renin activity and aldosterone used ethylenediaminetetraacetic acid as the anticoagulant; heparin was used in the samples for cortisol.

Serum and urinary sodium and potassium concentrations were measured by flame photometry (model 143; Instrument Laboratories, Inc., Watertown, MA) using lithium as the internal standard. Plasma and urine osmolalities were measured by freezing point depression with a Fiske Osmometer (model OS; Fiske Associates, Inc., Burlington, MA). Urine and plasma inulin concentrations were measured by the method of Heyrovsky (18), in which inulin is hydrolyzed to fructose by treatment with concentrated $\mathrm{HCl}$ and heat. Fructose then reacts with indole-3-acetic acid to form a purple complex. Urine and plasma PAH concentrations were measured by the method of Brun (19), in which PAH reacts with $p$-dimethylaminobenzaldehyde at a low $\mathrm{pH}$ to form a yellow complex. Spectrophotometric analysis of standard solutions and urine and plasma specimens allows calculation of inulin and PAH concentrations. Plasma renin activity was measured by the radioimmunoassay method of Sealey and Laragh (20). The intraassay coefficient of variation for plasma renin activity is $6 \%$, the interassay coefficient of variation is $9 \%$, and the sensitivity is $0.1 \mathrm{ng}$ angiotensin $\mathrm{I} / \mathrm{ml}$ per $\mathrm{h}$. Plasma aldosterone concentration was measured by the method of Bühler et al. (21). The intra- and interassay coefficients of variation are 6 and $8 \%$, respectively, and the sensitivity is $0.5 \mathrm{ng} / \mathrm{dl}$. Plasma cortisol (22) and serum prolactin (23) concentrations were measured by specific radioimmunoassays.

Calculations of renal function. Osmolar clearance $\left(C_{\text {osm }}\right)$ and free water clearance $\left(C_{\mathrm{H}_{2} \mathrm{O}}\right)$ were calculated by the following equations: $C_{\mathrm{osM}}=U_{\mathrm{osm}} \times \dot{V} / P_{\mathrm{osm}}$, and $C_{\mathrm{H}_{2} \mathrm{O}}=\dot{V}-C_{\mathrm{osM}}$, where $U_{\mathrm{osm}}=$ urine osmolality (milliosmoles per kilogram); $\boldsymbol{P}_{\text {osm }}=$ plasma osmolality (milliosmoles per kilogram); and $\dot{V}=$ urine flow (milliliters per minute).

Clearances of inulin (GFR) and PAH (RPF) were calculated by standard formulae. RBF was calculated as RPF/1-hematocrit. The absolute excretion rate $U_{\mathrm{x}} V$, where $U_{\mathrm{x}}=$ urine concentration of substance $x$, and the clearance $\left(C_{\mathrm{x}}\right)$ were calculated for sodium and potassium. The fractional excretion $\left(F e_{\mathbf{x}}\right)$ of each was calculated by the formula $F e_{\mathrm{x}}=\left(C_{\mathrm{x}} / \mathrm{GFR}\right) \times 100$. Filtration fraction was calculated as GFR/ RPF. Renal vascular resistance was calculated as mean arterial pressure (MAP)/RBF. Resistance units were converted from millimeters of mercury per milliliter per second to dynes $\cdot$ seconds $\cdot$ centimeters $^{-5}$ by multiplying by 1,332 .

Statistical analysis. Statistical analysis was carried out using paired $t$ tests and/or analysis of variance, as appropriate, to compare differences between base-line values and values obtained at time points after administration of SKF 82526-J or placebo, as appropriate. Blood pressure and heart rate responses before and after administration of SKF 82526-J in hypertensive patients also were analyzed by regression analysis with a test of homogeneity of slopes to determine the presence of change over time. Wilcoxons' rank sum test was employed to document the absence of change in the placebo period in more sensitive fashion. All data are reported as mean $\pm 1 \mathrm{SE}$, and $P$ values $<0.05$ are considered significant.

\section{Results}

Characteristics of the study subjects. The characteristics of the normal subjects on study day 0 and the hypertensive subjects on study day 6 in balance at $150 \mathrm{meq}$ sodium, $60 \mathrm{meq}$ potassium intake on the day before administration of SKF 82526-J are shown in Table I. No significant difference between normal and hypertensive subjects was observed with respect to body weight, serum sodium, or potassium concentrations, urinary sodium, or potassium excretion. Systolic and diastolic blood pressures and heart rates were significantly higher both

Table I. Characteristics of the Subjects Before Study

\begin{tabular}{|c|c|c|c|}
\hline & $\begin{array}{l}\text { Normal } \\
\text { subjects }\end{array}$ & $P$ & $\begin{array}{l}\text { Hypertensive } \\
\text { patients }\end{array}$ \\
\hline Body weight $(l b)$ & $162 \pm 3$ & NS & $165 \pm 4$ \\
\hline Serum sodium (meq/liter) & $140 \pm 1$ & NS & $139 \pm 2$ \\
\hline Serum potassium (meq/liter) & $4.3 \pm 0.1$ & NS & $4.1 \pm 0.2$ \\
\hline Urinary sodium (meq/24h) & $134 \pm 6$ & NS & $146 \pm 8$ \\
\hline Urinary potassium (meq/24 $h$ ) & $46 \pm 6$ & NS & $56 \pm 6$ \\
\hline \multicolumn{4}{|l|}{ Supine blood pressure $(\mathrm{mmHg})$} \\
\hline Systolic & $110 \pm 4$ & $<0.01$ & $156 \pm 1$ \\
\hline Diastolic & $63 \pm 4$ & $<0.01$ & $100 \pm 1$ \\
\hline Supine heart rate (beats/min) & $70 \pm 4$ & $<0.05$ & $78 \pm 1$ \\
\hline \multicolumn{4}{|l|}{ Upright blood pressure $(\mathrm{mmHg})$} \\
\hline Systolic & $112 \pm 5$ & $<0.01$ & $158 \pm 2$ \\
\hline Diastolic & $68 \pm 4$ & $<0.01$ & $105 \pm 1$ \\
\hline Upright heart rate (beats/min) & $74 \pm 4$ & $<0.01$ & $88 \pm 1$ \\
\hline
\end{tabular}


in the supine and upright position in the hypertensive patients than in the normal subjects, as expected.

Studies in hypertensive patients. Fig. 2 depicts the blood pressure and heart rate responses to a single oral dose (100 $\mathrm{mg}$ ) of SKF 82526-J in the 10 hypertensive patients. Each blood pressure data point represents the average of six readings at 5-min intervals obtained during the preceding $30 \mathrm{~min}$ for each patient. During the 180 -min control period, blood pressure and heart rate were stable. At time 0 immediately before administration of SKF 82526-J, blood pressure was 156 \pm 6 / $105 \pm 4 \mathrm{mmHg}$ and heart rate was $76 \pm 5$ beats/min. In response to SKF 82526-J, blood pressure decreased to $144 \pm 5 / 91 \pm 5$ $\mathrm{mmHg}$ at $60 \mathrm{~min}$, and to $141 \pm 5 / 89 \pm 8 \mathrm{mmHg}$ at $90 \mathrm{~min}$, and remained decreased at $145 \pm 6 / 99 \pm 3 \mathrm{mmHg}$ at $210 \mathrm{~min}(P$ $<0.0001)$. The reduction in blood pressure was associated with an increase in heart rate to $91 \pm 5$ beats $/ \mathrm{min}$ at $90 \mathrm{~min}(P$ $<0.002$ ).

Fig. 3 shows the effects of SKF $82526-J 100 \mathrm{mg}$ on renal hemodynamics. As shown in the upper panel of Fig. 3, RBF was stable at -30 and $0 \mathrm{~min}$ of the study. At $60 \mathrm{~min}$ after SKF 82526-J administration, RBF increased from $379 \pm 61$ to $529 \pm 75 \mathrm{ml} / \mathrm{min}(P<0.05)$ and peaked at $640 \pm 110 \mathrm{ml} / \mathrm{min}$ at $120 \mathrm{~min}$ after SKF 82526-J administration. As shown in the middle panel, renal vascular resistance decreased sharply from control values of $34 \pm 5$ dyn s cm$~^{-5} \times 10^{3}$ to a nadir of $19 \pm 3$ dyn s cm ${ }^{-5} \times 10^{3}$ at 90 min after SKF 82526-J administration. As illustrated in the lower panel, GFR was not altered by SKF 82526-J. Thus, filtration fraction decreased as a result of SKF 82526-J.

Fig. 4 shows the effects of SKF 82526-J on renal excretory function. As shown in the top panel, urine volume was stable at -30 and 0 min of the control period. In response to SKF 82526-J, urine volume increased in stepwise fashion and was significantly elevated from control during the last three collec-

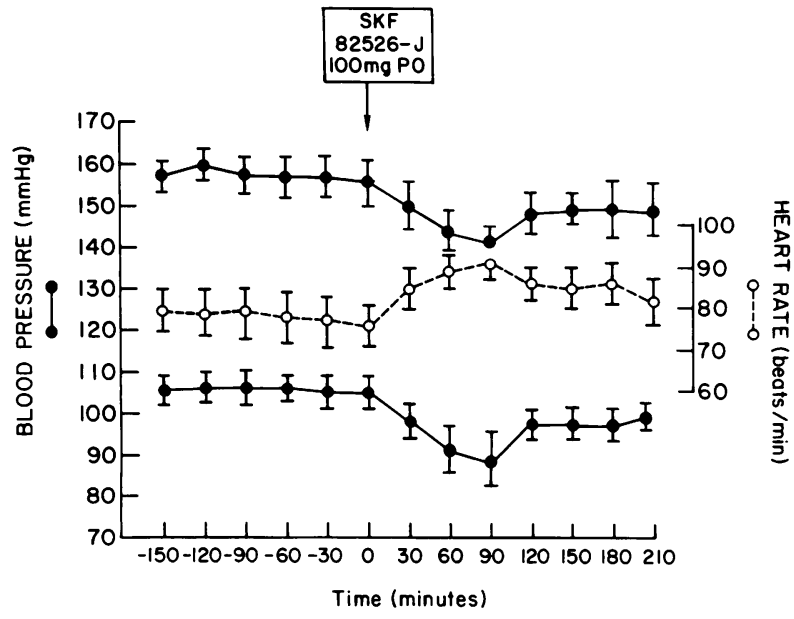

Figure 2. Blood pressure (systolic above and diastolic below) and heart rate responses to a single oral dose of SKF 82526-J in hypertensive patients $(n=10)$ in the supine position on study day 7 .
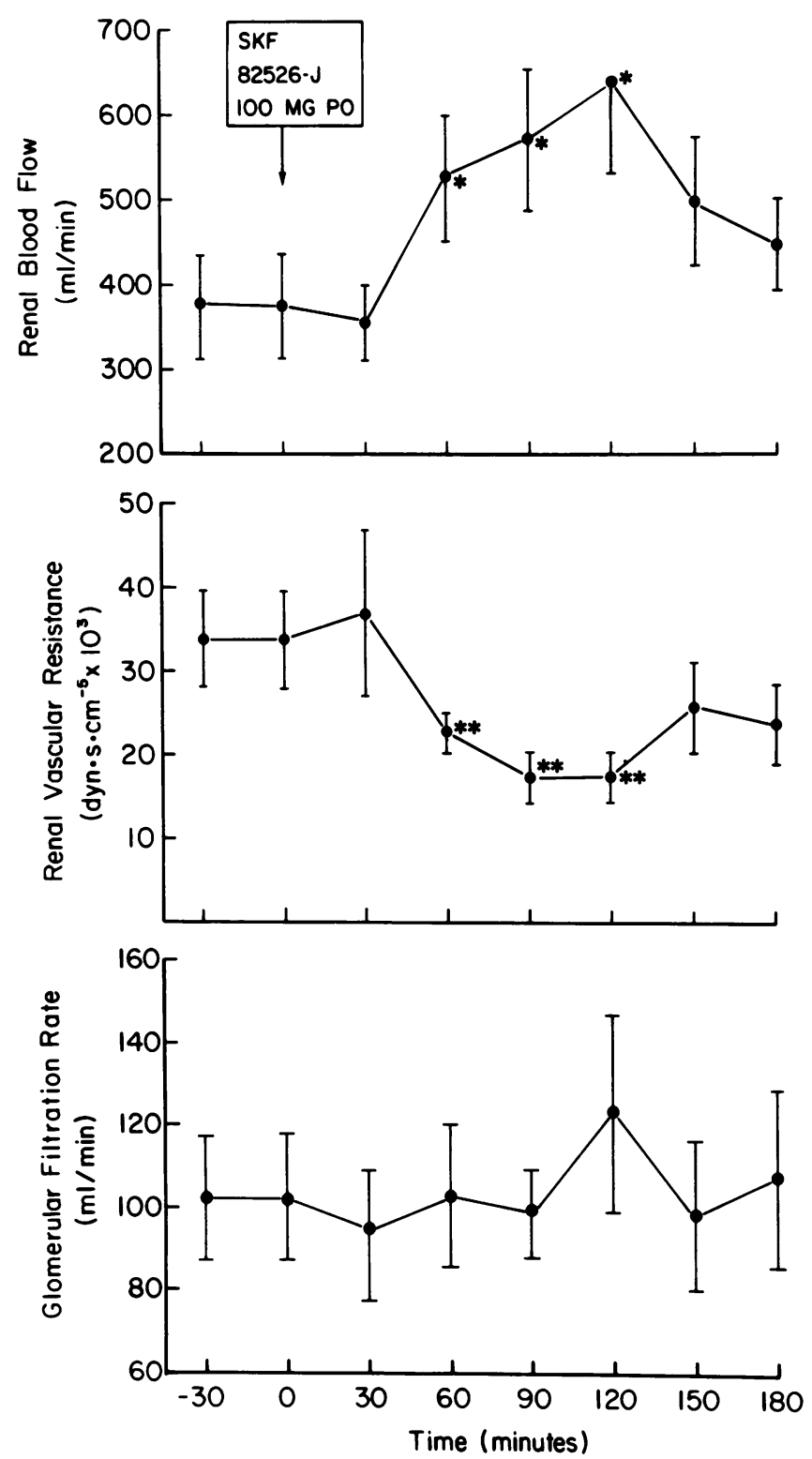

Figure 3. Effects of a single oral dose of SKF 82526-J on RBF (top), and renal vascular resistance (middle), and GFR (bottom) in hypertensive patients $(n=10)$ in the supine position on study day 7 .

Asterisks refer to statistically significant differences from base line: ${ }^{*} P$ $<0.05 ; * * P<0.01$.

tion periods. As shown in the middle panel, urinary sodium excretion was significantly increased, from a zero control value of $6.4 \pm 1.3 \mu \mathrm{eq} / \mathrm{min}$ to $12.1 \pm 2.5 \mu \mathrm{eq} / \mathrm{min}$ only at $120 \mathrm{~min}$ after SKF 82526-J administration. As shown in the lower panel, fractional sodium excretion was significantly elevated from 120 to $150 \mathrm{~min}$ after SKF 82526-J. Osmolar clearance was unaffected by SKF 82526-J, but free water clearance increased $(P<0.001)$ during the last collection period. Urinary 

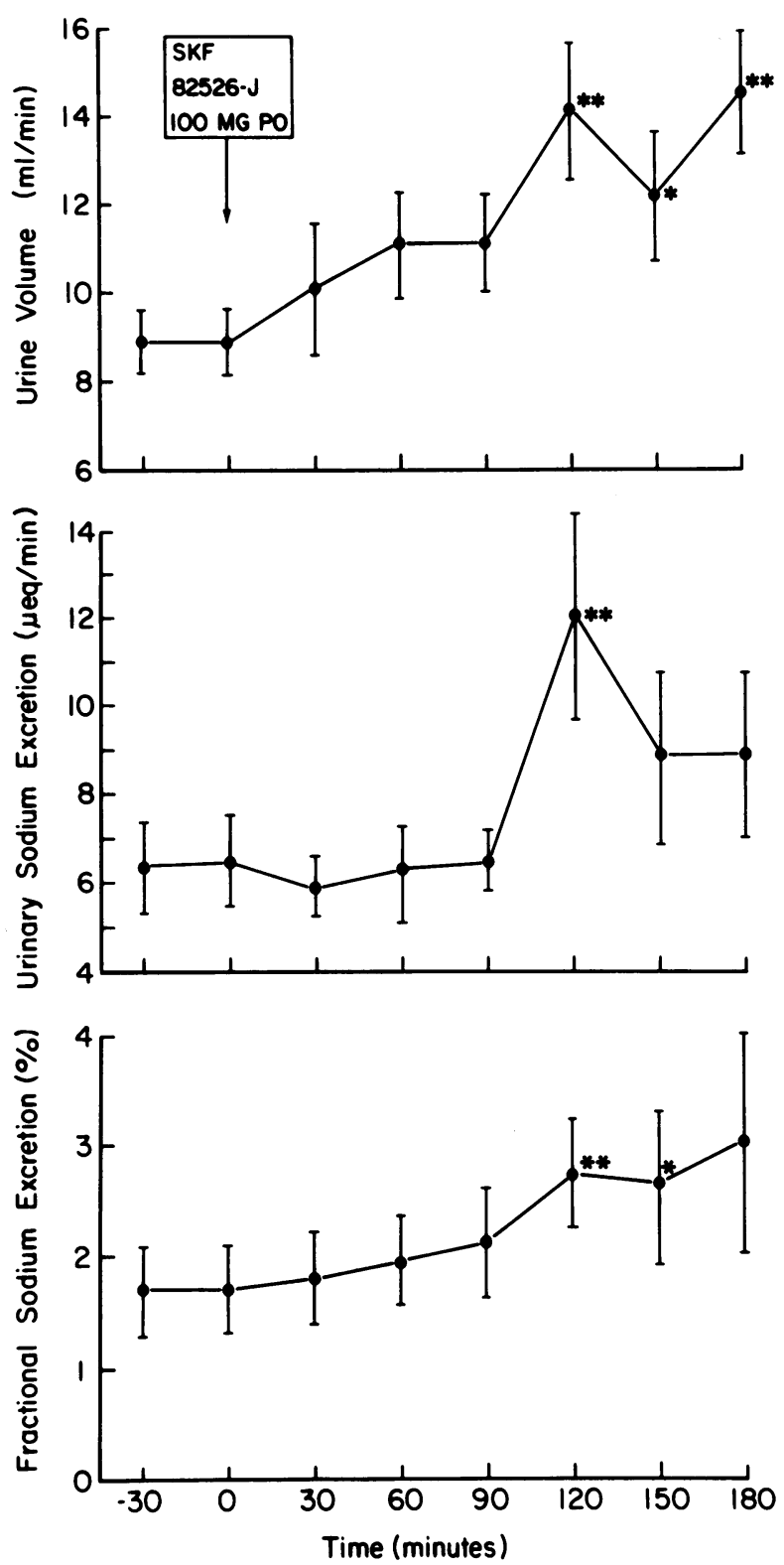

Figure 4. Effects of a single oral dose of SKF 82526-J on urine volume (top), urinary sodium excretion (middle), and fractional sodium excretion (bottom) in hypertensive patients $(n=10)$ in the supine position on study day 7 . Asterisks refer to statistically significant differences from base line: ${ }^{*} P<0.05 ;{ }^{* *} P<0.01$.

excretion and fractional excretion of potassium were unaltered by SKF 82526-J.

As shown in Table II, plasma renin activity increased from base-line values of $2.4 \pm 1.1$ to $3.5 \pm 1.5 \mathrm{ng} / \mathrm{ml}$ per h $(P<0.05)$ at $60 \mathrm{~min}$ after SKF 82526-J and continued to increase in stepwise fashion to a peak of $4.4 \pm 1.7 \mathrm{ng} / \mathrm{ml}$ per $\mathrm{h}(P<0.01)$ at $90 \mathrm{~min}$ of the study. Plasma aldosterone concentrations, however, were not significantly changed by SKF 82526-J. Similarly, serum prolactin concentrations were not affected by the selective DA-1 agonist. Serum sodium and potassium also were unaltered by SKF 82526-J.

Systemic hemodynamic changes for the entire inpatient phase of the study are shown in Figs. 5 and 6. Each data point represents the average of 24 measurements of blood pressure and heart rate for each subject in either the supine or upright position. Fig. 5 shows blood pressure and heart rate responses to SKF 82526-J with the subjects in the supine position. Blood pressure was stable at $155 \pm 1 / 100 \pm 0.4 \mathrm{mmHg}$ during $6 \mathrm{~d}$ of placebo administration. In response to SKF 82526-J $100 \mathrm{mg}$ four times a day, blood pressure decreased to $136 \pm 1 / 87 \pm 1$ $\mathrm{mmHg}(P<0.0001)$ at $2 \mathrm{~d}$ and remained significantly decreased for the remainder of the inpatient study. Heart rate with the hypertensive subjects in the supine position was only transiently increased $(P<0.05)$ on the first day of SKF 82526-J, and the overall heart rate response was not significantly altered.

Regression analysis was performed to determine the stability of blood pressure and heart rate before and after administration of SKF 82526-J. The slope of the line representing systolic and diastolic blood pressures with placebo (days 1-6) is similar to the slope with SKF 82526-J, but the $y$-intercept of systolic and diastolic pressure with placebo is different from that with SKF 82526-J. Thus, after the initial reduction of blood pressure by SKF 82526-J, blood pressure remained at the same level throughout the $7 \mathrm{~d}$ of SKF 82526-J administration. In contrast, the slope of the line representing pre-treatment heart rate differed significantly from the slope of the post-treatment heart rate $(P<0.0001)$, with post-treatment values declining steadily from day 7 to day 11 .

Fig. 6 shows blood pressure and heart rate responses to SKF 82526-J with the subjects in the erect position. Blood pressure was stable at $159 \pm 3 / 105 \pm 1 \mathrm{mmHg}$ before SKF 82526$J$ administration. SKF decreased blood pressure to $137 \pm 4$ / $94 \pm 2$ on day 7 and to $139 \pm 2 / 92 \pm 1$ on day $8(P<0.0001)$. Thereafter, blood pressure remained in the same range. A transient increase in heart rate $(P<0.01)$ on day 7 only, also was observed with the subjects in the erect position. The slope and intercept relationships of lines representing blood pressure and heart rate pre- and post-SKF 82526-J with the subjects upright were similar to those for the supine position.

For the entire inpatient phase, no significant differences in $24 \mathrm{~h}$ urinary volume, or sodium or potassium excretion were observed in response to SKF 82526-J.

Figs. 7 and 8 show the blood pressure response to SKF 82526-J on a weekly basis for the entire study, including the last 4-wk outpatient phase. Fig. 7 depicts blood pressures with the subjects in the supine position and Fig. 8 shows similar data with the subjects in the upright position. With continued administration of the compound, blood pressure variability increased but blood pressure remained significantly lower than control for 2 wk more. After discontinuation of SKF 82526-J, blood pressure increased to control levels after 2 wk. 
Table II. Hormonal and Metabolic Responses to SKF 82526-J in Patients with Essential Hypertension $(n=10)$

\begin{tabular}{|c|c|c|c|c|c|c|c|}
\hline & \multirow[b]{2}{*}{ Control } & \multicolumn{6}{|c|}{ Time $(\mathrm{min})$ after SKF $82526-\mathrm{J} 100 \mathrm{mg}$ orally } \\
\hline & & 30 & 60 & 90 & 120 & 150 & 180 \\
\hline \multicolumn{8}{|l|}{ Serum sodium } \\
\hline (meq/liter) & $139.3 \pm 2.2$ & $139.3 \pm 2.0$ & $139.3 \pm 2.2$ & $139.4 \pm 2.1$ & $139.6 \pm 1.9$ & $138.4 \pm 2.1$ & $137.0 \pm 0.9$ \\
\hline \multicolumn{8}{|l|}{ Serum potassium } \\
\hline (meq/liter) & $4.1 \pm 0.2$ & $4.2 \pm 0.2$ & $4.0 \pm 0.1$ & $4.0 \pm 0.2$ & $3.9 \pm 0.2$ & $3.9 \pm 0.1$ & $3.9 \pm 0.2$ \\
\hline \multicolumn{8}{|c|}{ Plasma renin activity } \\
\hline (ng/ml per $h$ ) & $2.4 \pm 1.1$ & $2.6 \pm 1.1$ & $3.5 \pm 1.5^{*}$ & $4.4 \pm 1.7^{*}$ & $3.4 \pm 1.2^{*}$ & $4.0 \pm 1.5 \ddagger$ & $3.4 \pm 1.6$ \\
\hline \multicolumn{8}{|c|}{ Plasma aldosterone } \\
\hline$(n g / d l)$ & $10.0 \pm 1.3$ & $10.2 \pm 2.2$ & $10.8 \pm 2.1$ & $10.7 \pm 1.7$ & $12.5 \pm 1.7$ & $12.9 \pm 2.0$ & $11.6 \pm 3.0$ \\
\hline \multicolumn{8}{|l|}{ Plasma cortisol } \\
\hline$(\mu g / d l)$ & $12.3 \pm 2.3$ & $12.6 \pm 2.5$ & $13.6 \pm 2.4$ & $12.6 \pm 2.1$ & $17.8 \pm 2.1$ & $13.1 \pm 2.6$ & $11.1 \pm 2.1$ \\
\hline \multicolumn{8}{|l|}{ Serum prolactin } \\
\hline$(n g / m l)$ & $10.2 \pm 1.4$ & $8.2 \pm 1.4$ & $8.7 \pm 1.1$ & $9.5 \pm 1.1$ & $11.3 \pm 1.9$ & $10.8 \pm 1.6$ & $11.1 \pm 1.8$ \\
\hline
\end{tabular}

$* P<0.05 ; \quad \mp P<0.01$.

In one patient, generalized cutaneous flushing developed $\sim 90$ min after the first dose of SKF 82526-J and lasted $\sim 3$ h. With continued administration of SKF 82526-J, flushing decreased gradually and progressively over a period of $4 \mathrm{~d}$, after which no further flushing occurred. No other untoward effects of the DA-1 agonist were observed.

Studies in normal subjects. Fig. 9 illustrates blood pressure responses in the supine and upright positions to sequential administration of SKF 82526-J (100 mg) or placebo. Each blood pressure data point represents the average of three readings at $1 \mathrm{~min}$ intervals for each subject. During the 120 min control period, blood pressure was stable. At time 0 immediately before administration of placebo or SKF 82526$\mathrm{J}$, supine blood pressure (upper panel) was $110 \pm 3 / 64 \pm 2$ and

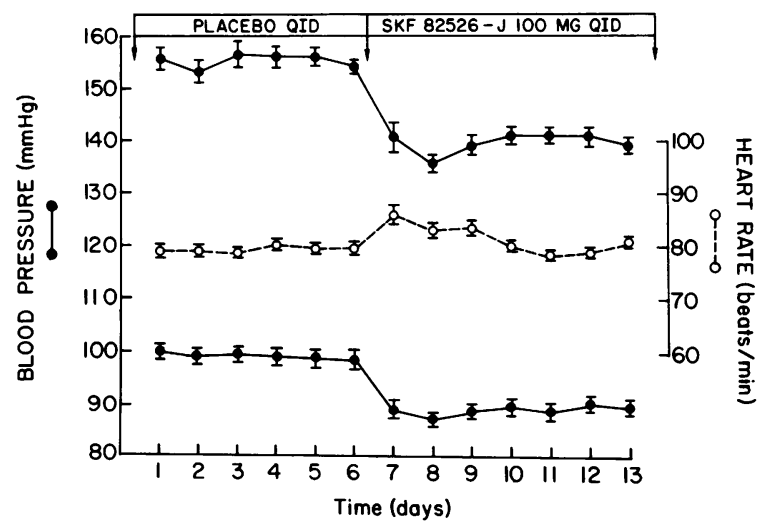

Figure 5. Blood pressure (systolic above and diastolic below) and heart rate responses to placebo and SKF 82526-J of hypertensive patients $(n=10)$ in the supine position on study days 1-13. QID, four times a day.
$113 \pm 3 / 68 \pm 4 \mathrm{mmHg}$, respectively $(P, \mathrm{NS})$. In response to the first dose of SKF 82526-J, supine diastolic blood pressure decreased from base-line values only at $120 \mathrm{~min}$ to $53 \pm 3$ $\mathrm{mmHg}(P<0.01)$ and was significantly lower than values after placebo at 90,120 , and $150 \mathrm{~min}(P<0.05)$. Supine systolic pressure was significantly higher than base line at $150 \mathrm{~min}$. Otherwise, no significant change of supine blood pressure from base-line values was observed with SKF 82526-J or placebo. Upright blood pressures (lower panel) at time 0 were $109 \pm 3$ / $74 \pm 2$ and $112 \pm 2 / 69 \pm 3 \mathrm{mmHg}(P, \mathrm{NS})$ before administration of placebo or SKF 82526-J, respectively. In response to SKF $82526-\mathrm{J}$, diastolic pressure decreased to $59 \pm 3 \mathrm{mmHg}(P$ $<0.05$ ) only at $120 \mathrm{~min}$ after the first dose. Otherwise, no alteration in upright blood pressures were observed in response to SKF 82526-J or placebo. No decrement in supine or upright

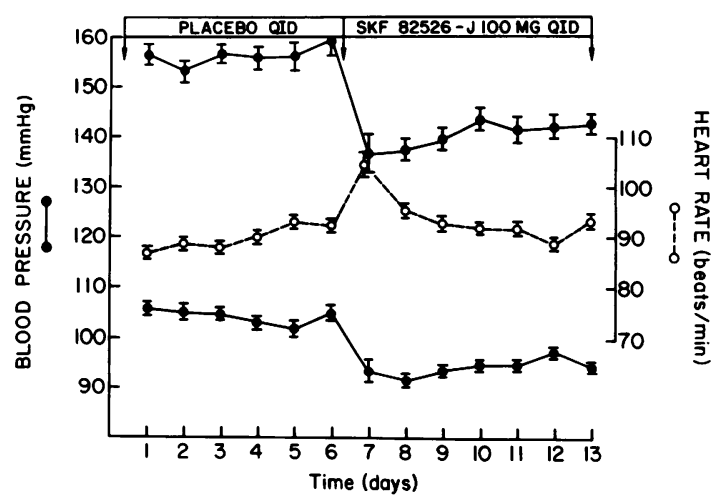

Figure 6. Blood pressure (systolic above and diastolic below) and heart rate responses to placebo and SKF 82526-J of hypertensive patients $(n=10)$ in the upright position on study days 1-13. QID, four times a day. 


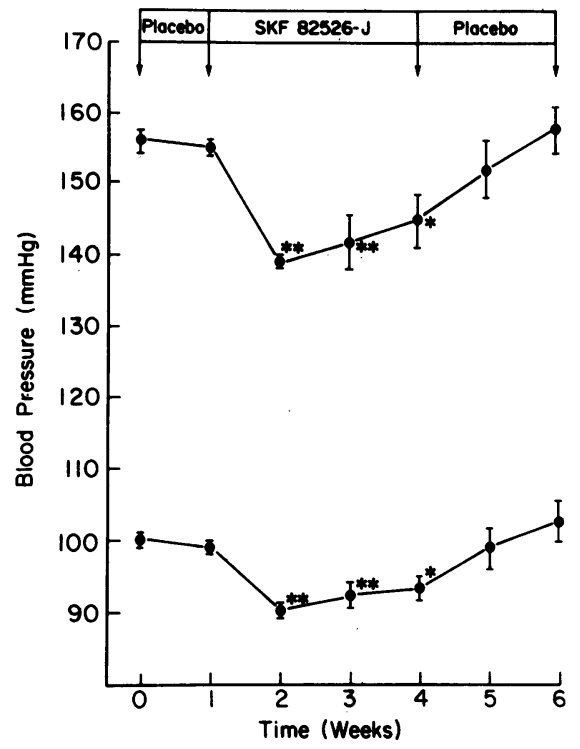

Figure 7. Blood pressure (systolic and diastolic) responses to placebo and SKF 82526-J four times a day in hypertensive patients $(n=10)$ in the supine position during the entire 6 wk of study. Asterisks refer to statistically significant differences from the initial placebo period: ${ }^{*} P<0.05 ;{ }^{* *} P<0.01$

blood pressure was observed after the second or third doses of SKF 82526-J.

Heart rate at time 0 in the supine position was $62 \pm 2$ beats/ min prior to placebo and $70 \pm 3$ beats/min before SKF 82526 -

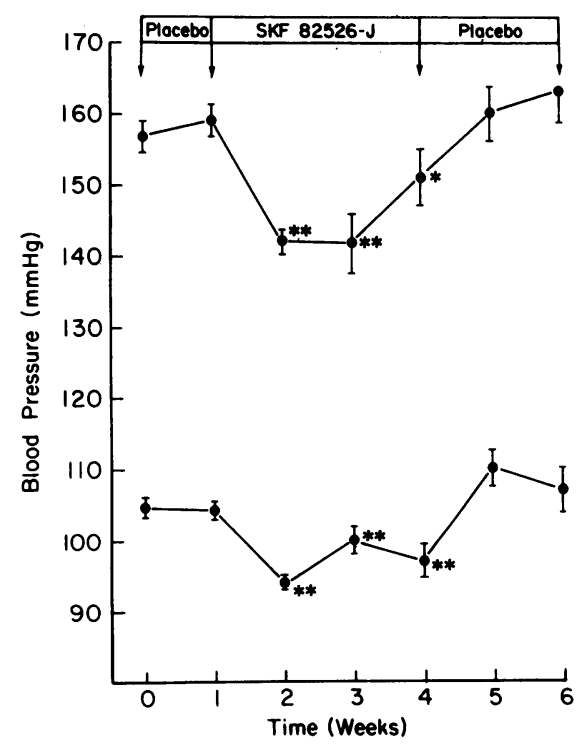

Figure 8. Blood pressure (systolic and diastolic) responses to placebo and SKF 82526-J four times a day in hypertensive patients $(n=10)$ in the upright position during the entire 6 wk of study. Asterisks refer to statistically significant differences from the initial placebo period: ${ }^{*} P<0.05 ;{ }^{* *} P<0.01$.
J. In the upright position, time 0 heart rate was $71 \pm 4$ and $79 \pm 5$ beats/min before placebo and SKF 82526-J, respectively. No significant alterations in heart rate from base-line values were observed in response to placebo or SKF 82526-J in either the supine or the upright position. Specifically, no increase in heart rate was observed at 120 min after the first dose of SKF 82526-J, when the only significant decrease in blood pressure was observed.

Fig. 10 depicts orthostatic changes in blood pressure in normal subjects and patients with essential hypertension in response to SKF 82526-J. In normal subjects, assumption of the upright position was associated with a significant increase in diastolic blood pressure $(P<0.05)$ in spite of SKF 82526$J$. In hypertensive patients, the decrement of blood pressure resulting from SKF 82526-J was not significantly different in the supine and upright positions.

No untoward effects of SKF 82526-J were observed in any of the normal subjects during this study.

\section{Discussion}

In 1964, Goldberg and colleagues (24) first demonstrated renal vasodilation by administration of intravenous dopamine to normal human subjects. Systemic arterial pressure was unchanged, and was possibly related to concurrent activation of alpha- and beta-adrenergic receptors as well as dopamine receptors (24). 2 yr later, Goldberg's group (25) reported that administration of dopamine $(1 \mu \mathrm{g} / \mathrm{kg}$ per $\min$ i.v.) to a hypertensive man increased arterial blood pressure. However, after administration of the alpha-adrenergic antagonist, phenoxybenzamine, an identical dose of dopamine markedly decreased peripheral vascular resistance and arterial pressure (25). Thus, Goldberg predicted that selective stimulation of peripheral DA-1 receptors should lower blood pressure by peripheral vasodilation (26).

Since that time, two peripheral dopamine receptors have been identified and characterized. DA-1 receptors subserve a vasodilator function, best observed in the renal vascular bed (26-30). Dopamine-2 (DA-2) receptors mediate inhibition of nerve-evoked norepinephrine release from sympathetic neurons and secretion of prolactin at pituitary lactotrophs $(30,31)$. Dopamine is a nonselective agonist at both DA-1 and DA-2 receptors, and has actions at alpha- and beta-adrenergic receptors as well (26-29). In Goldberg's initial experiments (25), alpha-adrenergic blockade by its antagonist action at presynaptic alpha-2-adrenergic receptors would have prevented DA-2 induced inhibition of norepinephrine release from sympathetic nerve endings. Thus, the depressor effect of dopamine in the presence of phenoxybenzamine (25) was probably due to selective activation of DA-1 receptors.

SKF 82526-J is an orally effective, selective peripheral DA1 agonist that is devoid of activity at DA-2, alpha- and betaadrenergic receptors $(13,14)$. Since the activity of SKF 82526$\mathrm{J}$ is confined to DA-1 receptor stimulation, the compound can 


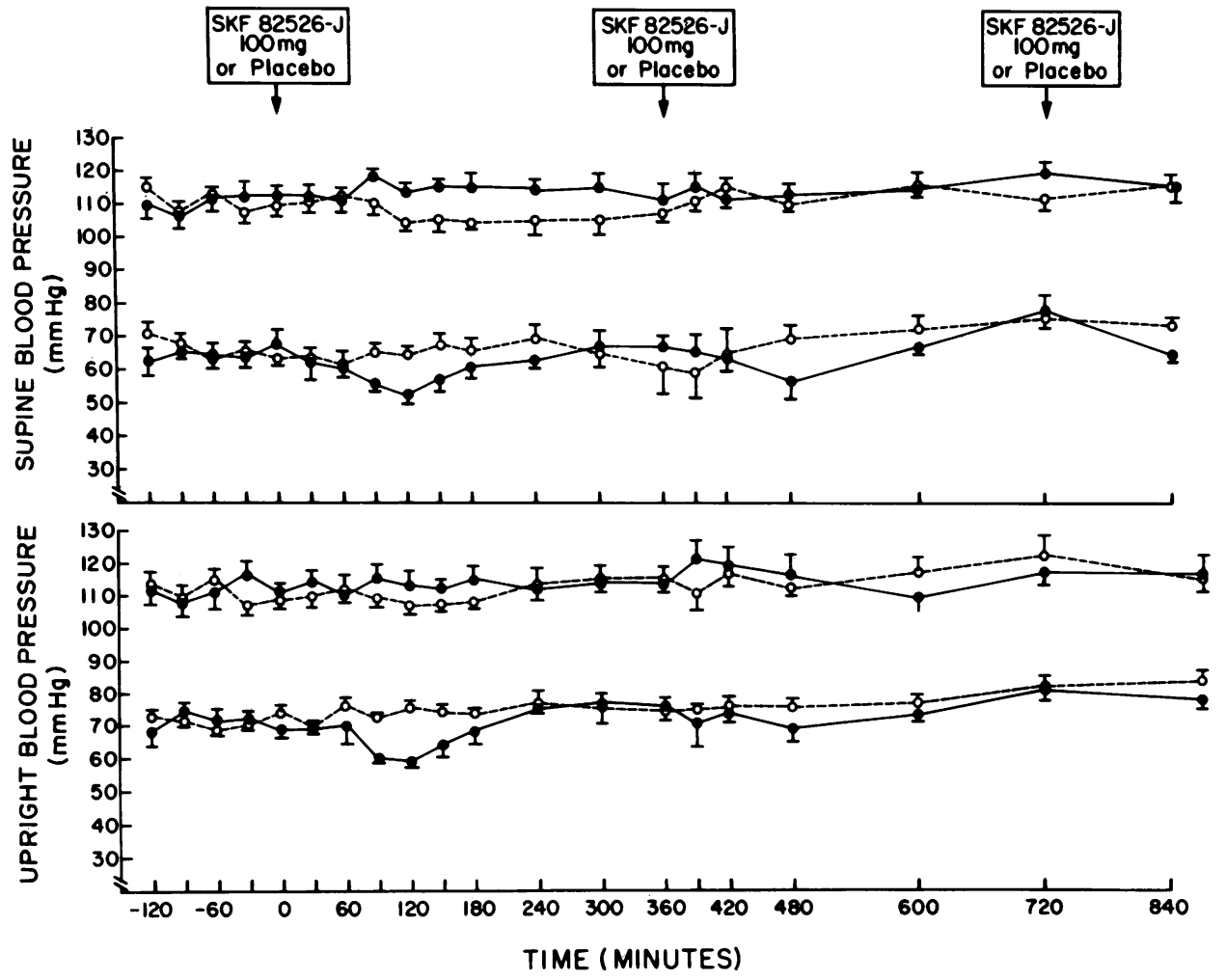

Figure 9. Blood pressure responses to SKF 82526-J (solid circles and lines) or placebo (open circles and dashed lines) in normal subjects ( $n$ $=5$ ) in the supine position (top) and in the upright position (bottom). be used as a heuristic tool to dissect the possible pathophysiological role of decreased dopaminergic vasodilator mechanisms in human essential hypertension. SKF 82526-J has been shown to produce renal vasodilation in normal human subjects with associated increase in urine volume, sodium excretion, fractional excretion of sodium, and free water clearance (17). Based on Goldberg's original observation (25), we hypothesized that selective DA-1 receptor stimulation should reduce blood pres-

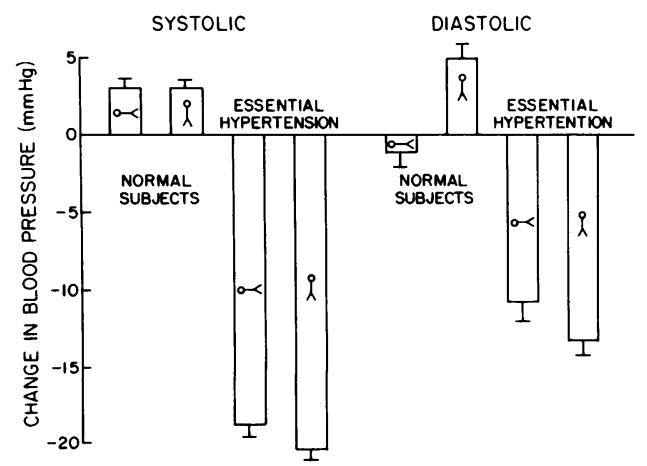

Figure 10. Orthostatic changes in blood pressure in normal subjects $(n=5)$ and in hypertensive patients $(n=10)$ after SKF 82526-J 100 $\mathrm{mg}$ four times a day for $24 \mathrm{~h}$. Supine and upright positions are depicted by the stick man characters within each bar. sure in hypertensive patients. We further hypothesized that DA-1 receptor stimulation would be associated with reduction in renal vascular resistance and augmentation of renal sodium and water excretion.

The results of the present study indicate that selective peripheral DA-1 receptor stimulation with fenoldopam (SKF 82526-J) does not appreciably alter blood pressure or heart rate in normal human subjects. In contrast, in patients with essential hypertension, DA-1 receptor stimulation decreases blood pressure to normal or near normal values. The hypotensive effect of the DA-1 agonist was apparent within $30 \mathrm{~min}$, continued administration was associated with sustained blood pressure reduction, and withdrawal of the compound was accompanied by redevelopment of the hypertension. These results are consistent with Goldberg's observations that the vasodilating action of dopamine in the presence of phenoxybenzamine is not associated with tachyphylaxis (26). These results indicate that reduced dopaminergic activity expressed at the vascular DA-1 receptor may contribute to the pathogenesis and/or maintenance of blood pressure in essential hypertension.

The observations of this study further suggest that selective DA-1 receptor stimulation with fenoldopam is not associated with orthostatic hypotension or sustained tachycardia. A transient tachycardia was present for only $24 \mathrm{~h}$, and heart rate reverted to control levels despite a continued depressor response. 
These findings contrast markedly with those of DA-2 receptor stimulation, in which orthostatic hypotension can readily be demonstrated (32-34). The orthostatic hypotension in this case is associated with venous pooling (34). In normotensive and hypertensive man, DA-2 stimulation is associated with suppression of circulating norepinephrine (32-34), suggesting an action by means of dopaminergic inhibition of sympathetic nervous system activity. Taken together, the evidence to date indicates that peripheral DA-1 receptor stimulation with fenoldopam reduces blood pressure by peripheral vasodilation with minor effects on sympathetic nervous system activity. Further studies of peripheral venous and arteriolar tone as well as sympathetic nervous system activity will be needed to define the precise mechanism of the antihypertensive action of DA-1 receptor stimulation.

In the present study, the acute reduction in blood pressure with DA-1 receptor stimulation with fenoldopam was associated with an increase in RBF and a marked reduction in renal vascular resistance. GFR was unchanged. The resulting decrease in filtration fraction suggests that DA-1 receptors mediate renal efferent arteriolar dilation. Recent elegant studies in isolated microdissected renal vessels have demonstrated a selective increase in efferent arteriolar tone by angiotensin II (35). In contrast, norepinephrine stimulates constriction of both afferent and efferent arterioles (35). Dopamine and angiotensin II may contribute jointly to intrarenal vascular regulation through selective effects on postglomerular arterioles. These intrarenal vascular effects could fully account for the demonstrated natriuretic effect of acute DA-1 receptor stimulation. Since fractional sodium excretion also increased, stimulation of a DA-1 receptor mediating an effect to inhibit sodium extrusion from luminal to interstitial surfaces of renal tubular cells also may play a role. Further studies in isolated renal tubular cells in experimental animals will be required to clarify these issues. However, from the results of this study, it is unlikely that natriuresis and reduction of extracellular fluid volume account for the sustained antihypertensive action of SKF 82526-J. No discernable changes in 24-h urinary electrolyte or volume excretion could be demonstrated after the first day of dopamine agonist administration.

The effects of SKF 82526-J on the renin-angiotensinaldosterone system deserve comment. Previous studies in normal subjects have indicated that aldosterone secretion may be inhibited by dopaminergic mechanisms (36-39). This concept is based on the observations in normal man that $(a)$ the dopamine antagonist, metoclopramide, stimulates aldosterone secretion (36), (b) metoclopramide-induced aldosterone secretion is blocked by dopamine in dose-dependent fashion (37), and $(c)$ dopamine inhibits angiotensin II-induced aldosterone secretion $(38,39)$. Since dopamine does not inhibit basal aldosterone secretion (37) and bromocriptine does not block the increase in aldosterone secretion induced by metoclopramide (37), aldosterone secretion has been regarded as being under maximum tonic dopaminergic inhibition by a receptor other than DA-2. In the present study, plasma aldosterone concentrations were not suppressed by DA-1 receptor stimulation, suggesting that the dopaminergic mechanism controlling aldosterone secretion may be unrelated to classical DA-1 or DA-2 receptors. Further studies to determine whether or not SKF 82526-J blocks metoclopramide-induced aldosterone secretion will be necessary to provide definitive information. Plasma renin activity increased slightly but significantly in response to acute administration of SKF 82526-J. This increase in plasma renin activity, which may have been baroreceptor mediated, could possibly have masked inhibition of aldosterone secretion by DA-1 stimulation. Recently, Barger and colleagues (40) demonstrated that intrarenal administration of dopamine stimulates renin release directly in the absence of an effect at alpha- or beta-adrenergic receptors. The results of the present study suggest that stimulation of renin release may be related to selective DA-1 receptor stimulation, since bromocriptine has no acute effects on plasma renin activity in man (34).

As in experimental animal studies, SKF 82526-J had no demonstrable effect on serum prolactin concentration. This observation supports the well-accepted concept that this benzazepine derivative is inactive at DA-2 receptors $(13,14)$.

In summary, in patients with essential hypertension specific DA-1 receptor stimulation with fenoldopam decreases blood pressure in sustained fashion. The acute decrease in blood pressure is associated with increased RBF, urine volume, sodium excretion, and reduction in renal vascular resistance. The longer term reduction in blood pressure is not associated with orthostatic hypotension or appreciable tachycardia. In contrast, DA-1 receptor stimulation in normal individuals exerts negligible depressor activity. These results suggest that reduced dopaminergic activity expressed at the peripheral DA1 receptor may contribute to the pathophysiology and/or maintenance of increased blood pressure in essential hypertension. These studies also indicate that selective DA-1 receptor stimulation may provide an effective alternative approach to treatment of chronic essential hypertension in the future.

\section{References}

1. Goldblatt, H., J. Lynch, and R. F. Hanzal. 1934. Studies on experimental hypertension, I. The production of persistent elevation of systolic blood pressure by means of renal ischemia. J. Exp. Med. 59:347-350.

2. Guyton, A. C., H. J. Granger, and T. G. Coleman. 1971. Autoregulation of the total systemic circulation and its relation to control of cardiac output and arterial pressure. Circ. Res. 28(Suppl. I):93-97.

3. Coleman, T. G., H. J. Granger, and H. C. Guyton. 1971. Whole body circulatory autoregulation and hypertension. Circ. Res. 28(Suppl. II): $79-86$.

4. Brod, J. V., Z. Fencl, H. I. Jirka, and M. Ulrych. 1962. General and regional hemodynamic pattern underlying essential hypertension. Clin. Sci. 23:339-349.

5. Brod, J. V. 1960. Essential hypertension. Hemodynamic observations bearing on pathogenesis. Lancet. 1:773-778. 
6. Reubi, F. C., P. Weidmann, J. Holder, and P. T. Cottier. 1978. Changes in renal function in essential hypertension. Am. J. Med. 64:556-563.

7. Hollenberg, N. K., L. J. Borucki, and D. F. Adams. 1978. The renal vasculature in early essential hypertension: evidence for a pathogenic role. Medicine (Rochester). 57:167-178.

8. Tarazi, R. C., and J. Conway. 1983. The hemodynamics of hypertension: regional hemodynamics. In Hypertension. Second ed. J. Genest, O. Kuchel, P. Hamet, and M. Cantin, editors. McGraw-Hill Book Co., New York. 31-42.

9. Hollenberg, N. K., D. F. Adams, H. Solomon, W. R. Chenitz, B. M. Burger, H. L. Abrams, and J. P. Merrill. 1975. Renal vascular tone in essential and secondary hypertension: hemodynamic and angiographic responses to vasodilators. Medicine (Rochester). 54:2944.

10. Weinstock, J., J. W. Wilson, D. L. Ladd, C. K. Brush, F. R. Pfeiffer, G. Y. Kuo, K. C. Holden, C. F. Kim, R. A. Hahn, J. R. Wardell, Jr., A. J. Tobia, P. E. Setler, H. M. Sarau, and P. T. Ridley. 1980. Separation of potent central and renal dopamine agonist activity in substituted 6-chloro-2,3,4,5-tetrahydro-7,8-dihydroxy-1-phenyl-1H3-benzazepines. J. Med. Chem. 23:973-975.

11. Mann, W. A., G. F. Sosnowski, B. J. Kavanaugh, R. W. Erickson, F. T. Brennan, and V. D. Wiebelhaus. 1981. Comparative properties of two benzazepine renal vasodilator compounds: SKF38393$\mathrm{C}$ and 82526-J. Fed. Proc. 40:647.

12. Brennan, F. T., B. J. Kavanaugh, and V. D. Wiebelhaus. 1981. Combination studies with the renal vasodilator, SKF 82526-J and hydrochlorothiazide. Fed. Proc. 40:648.

13. Hahn, R. A., J. R. Wardell, H. M. Sarau, and P. T. Ridley. 1982. Characterization of the peripheral and central effects of SKF 82526, a novel dopamine receptor agonist. J. Pharmacol. Exp. Ther. 223:305-313.

14. Weinstock, J., J. W. Wilson, D. L. Ladd, M. Brenner, D. M. Ackerman, A. L. Blumberg, F. T. Brennan, R. A. Hahn, J. P. Hieble, H. M. Sarau, and V. D. Wiebelhaus. 1983. Dopaminergic benzazepines with divergent cardiovascular profiles. Am. Chem. Soc. Symp. Series. 224:157-167.

15. Ackerman, D. M., J. Weinstock, V. D. Wiebelhaus, and B. Berkowitz. 1982. Renal vasodilators and hypertension. Drug. Dev. Res. 2:283-297.

16. Ackerman, D. M., A. L. Blumberg, J. P. McCafferty, S. S. Sherman, J. Weinstock, C. Kaiser, and B. Berkowitz. 1983. Potential usefulness of renal vasodilators in hypertension and renal disease: SKF 82526. Fed. Proc. 42:186-190.

17. Stote, R. M., J. W. Dubb, R. G. Familiar, B. B. Erb, and F. Alexander. 1983. A new oral renal vasodilator, fenoldopam. Clin. Pharmacol. Ther. 34:309-315.

18. Heyrovsky, A. 1956. A new method for determination of inulin in plasma and urine. Clin. Chim. Acta. 1:470-474.

19. Brun, C. 1951. A rapid method for the determination of paraaminohippuric acid in kidney function tests. J. Lab. Clin. Med. 37:955-958.

20. Sealey, J. E., and J. H. Laragh. 1979. How to do a plasma renin assay. Cardiovasc. Med. 2:1079-1092.

21. Bühler, F. R., J. E. Sealey, and J. H. Laragh. 1974. Radioimmunoassay of plasma aldosterone. In Hypertension Manual. J. H. Laragh, editor. Dun-Donnelley Publishing Corp., New York. 655-672.

22. Foster, L. B., and R. T. Dunn. 1974. Single antibody technique for radioimmunoassay of cortisol in unextracted serum or plasma. Clin. Chem. 20:365-368.
23. Sinha, Y. N., F. W. Selby, U. J. Lewis, and W. P. Vanderlaan. 1973. A homologous radioimmunoassay for human prolactin. J. Clin. Endocrinol. Metab. 36:509-516.

24. McDonald, R. H., Jr., L. I. Goldberg, J. L. McNay, and E. P. Tuttle. 1964. Effects of dopamine in man; augmentation of sodium excretion, glomerular filtration rate and renal plasma flow. J. Clin. Invest. 43:1116-1124.

25. McNay, J. L., K. L. MacCannell, M. B. Meyer, and L. I. Goldberg. 1966. Hypotensive effect of dopamine in dogs and hypertensive patients after phenoxybenzamine. J. Clin. Invest. 45:1045-1046.

26. Goldberg, L. I. 1972. Cardiovascular and renal actions of dopamine: potential clinical applications. Pharmacol. Rev. 24:1-29.

27. Goldberg, L. I., P. T. Volkman, and J. D. Kohli. 1978. A comparison of the vascular dopamine receptor with other dopamine receptors. Annu. Rev. Pharmacol. Toxicol. 18:57-79.

28. Goldberg, L. I. 1978. Vascular dopamine receptor as a model for other dopamine receptors. Adv. Biochem. Psychopharmacol. 19:119129.

29. Goldberg, L. I., and A. B. Weder. 1981. Connections between endogenous dopamine, dopamine receptors and sodium excretion: evidences and hypotheses. In Recent Advances in Clinical Pharmacology. P. Jurner and D. Shand, editors. MacMillan Publishing Co., New York. 149-166.

30. Lokhandwala, M. F., and R. J. Barrett. 1983. Dopamine receptor agonists in cardiovascular therapy. Drug. Dev. Res. 3:299310.

31. Kebabian, J. W., and D. B. Calne. 1979. Multiple receptors for dopamine. Nature (Lond.). 277:93-96.

32. Whitfield, L., J. R. Sowers, M. L. Tuck, and M. S. Golub. 1980. Dopaminergic control of plasma catecholamine and aldosterone responses to acute stimuli in normal man. J. Clin. Endocrinol. Metab. 51:724-729.

33. Kolloch, R., K. Kobayashi, and V. DeQuattro. 1980. Dopaminergic control of sympathetic tone and blood pressure: evidence in primary hypertension. Hypertension. 2:390-394.

34. Johns, D. W., C. R. Ayers, and R. M. Carey. 1984. The dopamine agonist bromocriptine induces hypotension by venous and arteriolar dilation. J. Cardiovasc. Pharmacol. 6:582-587.

35. Edwards, R. M. 1983. Segmental effects of norepinephrine and angiotensin II on isolated renal microvessels. Am. J. Physiol. 244:F526F534.

36. Carey, R. M., M. O. Thorner, and E. M. Ortt. 1979. Effects of metoclopramide and bromocriptine on the renin-angiotensin-aldosterone system in man: dopaminergic control of aldosterone. J. Clin. Invest. 63:727-735.

37. Carey, R. M., M. O. Thorner, and E. M. Ortt. 1980. Dopaminergic inhibition of metoclopramide-induced aldosterone secretion in man: dissociation of responses to dopamine and bromocriptine. $J$. Clin. Invest. 66:10-18.

38. Drake, C. R., N. V. Ragsdale, D. L. Kaiser, and R. M. Carey. 1984. Dopamine suppression of angiotensin II-induced aldosterone secretion in man: differential responses during sodium loading and depletion. Metab. Clin. Exp. 33:696-702.

39. Drake, C. R., and R. M. Carey. 1984. Dopamine modulates sodium-dependent aldosterone responses to angiotensin II in man. Hypertension. 6(Suppl. I):119-123.

40. Mizoguchi, H., V. J. Dzau, L. G. Siwek, and A. C. Barger. 1983. Effect of intrarenal administration of dopamine on renin release in conscious dogs. Am. J. Physiol. 244:H39-H45. 